\title{
Humor in University Teaching: Role of Teachers' Achievement Goals and Self-efficacy for their use of Content-related Humor
}

\author{
Daumiller, Martin, Bieg, Sonja, Dickhäuser, Oliver \& Dresel, Markus \\ Department of Psychology, University of Augsburg
}

Manuscript published in Studies in Higher Education:

Daumiller, M., Bieg, S., Dickhäuser, O., \& Dresel, M. (2019). Humor in university teaching:

Role of teachers' achievement goals and self-efficacy for their use of content-related humor.

Studies in Higher Education. Advanced online publication. doi:10.1080/03075079.2019.1623772

Please address correspondence to Martin Daumiller, Department of Psychology, University of Augsburg, Universitätsstr. 10, 86135 Augsburg, Germany, Tel.: +49 821 598-5610, E-Mail: martin.daumiller@phil.uni-augsburg.de.

(1) 2019, Routledge. This paper is not the copy of record and may not exactly replicate the final, authoritative version of the article. Please do not copy or cite without authors permission. The final article is available via its DOI: 10.1080/03075079.2019.1623772 


\begin{abstract}
Teachers' content-related humor matters for the quality of higher education, however, little is known about the circumstances under which teachers use it. From a socio-cognitive perspective, teachers' achievement goals and self-efficacy appear to be relevant personal precursors. We investigated their effects on content-related humor in two studies. In Study 1, 229 teachers (79 female; 159 PhDs; 33 full professors) participated with 387 courses while 10,296 students assessed the humor in these courses. Study 2 used a similar design for 45 teachers ( 20 female; 27 PhDs, 9 full professors), 116 course sessions, and 2,333 student assessments. Three-levelanalyses pointed to substantial variance in students' assessments of content-related humor which could be attributed to differences between courses/sessions within teachers (ICC $=.12-.13$ ) and between teachers themselves (ICC=.21). In both studies, performance (appearance component) avoidance goals emerged as negative predictors, and relational goals and self-efficacy as positive predictors of content-related humor, highlighting the relevance of instructors' motivations for the use of instructional humor.
\end{abstract}

Keywords: humor, higher education teaching, instruction, achievement goals, self-efficacy, motivation 


\section{Humor in University Teaching: Role of Teachers' Achievement Goals and Self-efficacy for their use of Content-related Humor}

There is growing evidence that teachers' humor is relevant for teaching quality and student outcomes, with humor related to instructional content being highly functional (Wanzer, Frymier, and Irwin 2010). Despite the importance of content-related humor and its relations, it is largely unknown under which circumstances teachers use this type of humor in practice. The few investigations in this direction have focused on rather stable aspects, such as teachers' gender, teaching experience, and humorous orientation (Bryant et al. 1979; Sev'er and Ungar 1997; Wanzer et al. 2010). Since the stability of these aspects limits practical implications and can only account for small differences in teachers' use of humor, further personal aspects should be taken into consideration. From a socio-cognitive perspective, analyzing motivational differences between teachers appears to be a promising — however, until now, uninvestigated—personal approach to explain differences in the extent to which teachers use content-related humor. We tested this assumption in two studies in which we examined the effect of achievement goals and self-efficacy beliefs on students' assessments of higher education teachers' use of content-related humor within whole courses, and within individual course sessions.

\section{Content-related Humor in Higher Education Teaching}

At first thought, humor may appear to contradict the seriousness that constitutes science and higher education teaching (Powell and Andresen 1985; Vallance 1980). But just like humor is an aspect of good teaching in primary and secondary education, and is related to encouraging learning and motivation of students (see Banas, Dunbar, Rodrigues, and Liu 2011; Bieg and Dresel 2018; Horng, Hong, ChanLin, Chang, and Chu 2005), humor can also be considered as important for teaching in higher education. 
Empirically, this can be seen in students themselves, as they have been found to appraise instructional humor as a central characteristic of effective higher education teaching (Berk 1996; Delaney, Johnson, Johnson, and Traslan 2010; Lee, Kim, and Chan 2013). Furthermore, it is reported that the use of humor can help students to increase and sustain interest and attention in learning topics (Davis and Arrend 2013; McKeachie and Svinicki 2006). Earlier studies also documented that the extent of humor perceived by students varies between teachers and courses, and is linked to students' assessments of teaching quality (Bryant, Comisky, Crane, and Zillmann 1980), specifically with their learning gains (for an overview see Martin et al. 2006). Such effects vary in strength throughout literature, which may be traced back to different types of humor having been the focus of different studies (Banas, Dunbar, Rodrigues, and Liu 2011; Frymier et al. 2008; Wanzer, Frymier, Wojtaszczyk, and Smith 2006). Besides content-related humor (e.g. enhancing the presentation of the instructional content with a suitable joke), there is also humor without connection to teaching content, and humor which is carried out at the expense of others or the person themselves. While such inappropriate forms, or at least not clearly appropriate forms, of humor can be deemed detrimental for teaching quality and are often opposed by students (see Liu et al., 2017), content-related humor is considered to be the most functional and is associated with learning gains of students (Wanzer et al. 2010). The relevance of contentrelated humor for emotional experiences, student-teacher-relationships, as well as instructional clarity and interestingness was also demonstrated in studies with secondary school students (see Bieg and Dresel 2018; Bieg, Grassinger, and Dresel, 2017, 2018). Thus, we focus on contentrelated humor in the present work and seek to explain teachers' use of this type of humor.

Previous research about humor in instructional settings has mainly focused on its prevalence and effects, while little evidence is available concerning which teachers use humor 
and under which circumstances. Regarding the circumstances, it can be expected that the larger a course is, the more difficult humorous teaching becomes. This can be attributed to increased difficulty of engaging the students, increased distance between teachers and students, increased stress experiences, as well as reduced interactions with individual students (see Arvanitakis 2014; Schrader, Helmke, Hosenfeld, \& Ridder, 2001). Along with that, theories about humor describe when something is perceived as humorous and how it can affect learning (see overview at Banas et al. [2011]) but to the best of our knowledge, nothing is known about personal precursors of the use of instructional humor. The scarce research that does exist has focused on gender, teaching experience, and humorous orientation of teachers. The clarity of these findings is limited due to inconsistent findings and small sample sizes. In synopsis, they indicate that men tend to use more humor (Bryant et al. 1979; Sev'er and Ungar 1997), and the humor used by women is often more content-related (Bryant et al. 1979). Moreover, the more teaching experience they have, the more teachers seem to use humor (particularly more content-related humor; Javidi and Long's 1989). Finally, humorous orientation — an individual predisposition to be funny (S. Booth-Butterfield and M. Booth-Butterfield 1991) — is associated with more and rather multifaceted humor in teaching (Wanzer et al. 2010). However, this trait is considered barely variable (M. BoothButterfield and Wanzer 2010) and is likely not powerful enough for explaining further differences in the use of humor and enabling practical implications (which not only depend on the ability to produce humorous messages, but more importantly, on actually using them).

In consequence, such a dispositional perspective as it was used in previous research appears limited. On one hand, it provides restricted practical implications, and on the other hand, a high variance between individuals of the same gender, teaching experience, and humor orientation likely remains, which is indicative of the importance of taking further personal 
aspects into consideration. Furthermore, previous studies have indicated that instructional humor is often used spontaneously (e.g. Bryant et al. 1979). Since higher education teachers typically do not undergo explicit didactical preparation for teaching in higher education and there are many complex teaching and learning aspects in everyday teaching (Böss-Ostendorf and Senft 2010), it can be assumed that humor is often not used as an intentional instructional method but rather happens impromptu. As such, a direct encouragement of "more content-related humor in teaching" seems difficult (instead, a multimodal approach is likely required to foster humorous teaching). Taken together, this highlights the importance of investigating personal aspects that can be intentionally encouraged and supported.

Based on research on personal aspects underlying varying teaching behavior, teachers' achievement motivation can be considered an important factor, especially because instructional humor and achievement motivation are both embedded in social contexts. Teachers' achievement goals and self-efficacy beliefs are established motivational aspects that matter for differences in teaching behavior (e.g. Butler 2007; Bailey 1999; Ross 1992). They also seem to be important for the degree to which teachers use content-related humor. For example, the use of humor may be a viable way to achieve relational goals, and individuals who are worried about appearing incompetent, might refrain from using humor as they could embarrass themselves (e.g. by doing something that is not funny, or telling a joke in a bad way). At the same time, high confidence in teaching competences is likely required to integrate humor into teaching practice.

\section{Achievement Goals and Self-efficacy Beliefs as Frameworks to describe Teachers' Motivations}

Motivation describes the reasons and intentions underlying human behaviors. The current motivation in a specific achievement context (such as teaching) consists of expectations about the 
feasibility (expectancy component) and the desirability of behavior options (value component; Wigfield and Eccles 2000). Focused on these two components, individuals' preferences for achievement goals and their self-efficacy beliefs are established motivational constructs in educational psychology and relevant for describing motivational differences in teachers.

\section{Achievement goals}

Achievement goal theory (AGT) describes which kinds of goals individuals tend to pursue in achievement contexts (e.g. Dweck 1986; Elliot and Hulleman 2017; Nicholls 1984). Depending on their characteristics and focus, different goals can be classified as goal classes and represent a structured theoretical framework that is relevant for the initiation, implementation, and evaluation of behaviors. AGT has proven powerful in explaining and predicting achievement behaviors of various populations (for an overview see Elliot and Hulleman [2017]; Maehr and Zusho [2009]). Based on a comprehensive research body on students, AGT has also been successfully used to describe school teachers' and higher education teachers' motivations and their associations with their professional behaviors (see Butler [2007]; Daumiller, Dickhäuser, and Dresel [2019]).

In research on school teachers, five goal classes are distinguished: A teacher pursues a learning (approach) goal, if they are focused on learning something new and expanding professional competence- for example by trying new approaches in teaching. Performance approach goals describe an effort to be better than others and to make a good impression, for example in social interaction with colleagues, in teaching, or in front of superiors (see Nitsche, Dickhäuser, Fasching, and Dresel [2011]). A teacher pursues performance avoidance goals if they are aiming to not be worse than others and to hide a (putative) lack of competence, e.g. in difficult teaching situations or those with demanding content. Work avoidance goals (Nicholls 
1984) delineate a striving to minimize work efforts, e.g. when preparing or post processing lessons. Lastly, relational goals (Butler 2012) characterize the effort to build an amicable and valued relationship with the students.

Beyond these goal classes, it was suggested to differentiate performance goals further, depending on their focus on normative performance (e.g., be better than others) or their focus on appearance (e.g., making a good impression, irrespective of actual own competence) since these different aspects could be differentially associated with different cognitions and behaviors when teaching (Daumiller et al. 2019; Daumiller, Grassinger, Dickhäuser, and Dresel 2016; see also Hulleman et al. [2010]; Senko and Dawson [2017]). In terms of the use of humor, both aspects theoretically seem to be relevant. For example, teachers could use humor to be better than others (normative performance approach goals) or to make a good impression in front of students (appearance performance approach goals). Taking this reasoning into consideration, we will consider performance goals first on the superior level (i.e., performance approach and performance avoidance goals, without differentiation between appearance or normative component) to investigate their general effects; and will then test whether there are differences between appearance and normative goals regarding the use of content-related humor.

As mentioned before, preferences for achievement goals are systematically related to selfreported teaching behaviors in higher education (e.g., Daumiller et al. 2019). However, results that are not based on self-reports are rare. Daumiller et al. (2016) investigated the assessments of teaching quality of 9,241 students in 371 courses taught by 230 teachers and examined how student assessments of teaching quality relate to teachers' achievement goals. The results show that the overall evaluation of teaching quality was higher for teachers who reported high learning goals and high self-efficacy, and lower for teachers who reported strong performance avoidance 
goals. The research on school teachers documented similar effects for these goal classes (summarized by Butler [2014]), however neither for school teachers, nor for higher education teachers, we found investigations focused on how perceived humor or related constructs are associated with teachers' achievement goals.

Based on the above described functionality of the different goal classes for teaching behavior and the theoretical relevance of achievement goals for the valuation of behavior options (including those related to humorous teaching), it can be assumed that achievement goals are relevant for the use of content-related humor. Performance approach goals can be expected to be positively related to the use of content-related humor, as teachers likely regard the use of humor as suitable to meet their goals of demonstrating competence (e.g., being seen as a confident and versed teacher). Conversely, performance avoidance goals can be expected to go along with a reduced use of humor: Since humor is not received in the same way by everyone (Ruch 2001), teachers who attempt to be funny may not achieve this, but rather look bad instead (which is sought to be avoided when pursuing strong performance avoidance goals). Finally, the use of humor could be useful to reach goals concerning interpersonal contact and the quality of relationships. Opposed to these directed expectations, it was theoretically not clear how the use of humor would be relevant for learning goals and work avoidance goals. Particularly, associations in both directions are plausible, e.g., learning goals are known to be associated with favorable emotions and more joy in academic behavior, which could encourage the use of humor, besides being a good opportunity for further developing one's teaching skills — at the same time learning goals put a focus on the self and the learning material itself, which could diminish the use of humor.

\section{Self-efficacy beliefs}


Besides the desirability of behavior options, expectations regarding their attainability are a second important aspect of individual motivation. An established theoretical construct to describe such expectations are self-efficacy beliefs (Bandura 1977, 1997), i.e., subjective assumptions of individuals concerning the question of whether they can successfully carry out a certain action. Teacher self-efficacy refers to their beliefs of whether they are able to master pedagogically challenging situations, including supporting and encouraging learning and behavior of students, especially regarding unmotivated or problematic students (see TschannenMoran and Woolfolk Hoy 1998, 2001). For school teachers and higher education teachers alike, self-efficacy plays an important role for teaching behaviors and teaching outcomes (Bailey 1999; Ross 1992).

Numerous investigations have documented the relevance of self-efficacy beliefs for (mostly self-reported) teaching behaviors. Teachers with high self-efficacy beliefs also exhibit more favorable instructional behaviors, such as taking more intensive care of students with learning difficulties, teaching more innovatively and reflectively, using activating teaching techniques, and achieving a more favorable class atmosphere (for a summary of these findings, see: Klassen et al. [2014]; Schunk, Meece, and Pintrich [2013]).

Recently, higher education teachers' self-efficacy beliefs have also been investigated. This line of research distinguishes between multiple domains that higher education teachers are often active in, namely research, teaching, and administration/service (e.g., Major and Dolly 2003). Yet the focus of this line of research mostly lies on self-efficacy beliefs in the research domain (Forester, Kahn, and Hesson-McInnis 2004; Hemmings and Kay 2009), while selfefficacy beliefs for teaching are scarcely investigated. To describe their self-efficacy beliefs for teaching, similar conceptualizations and measures as for school teachers have been successfully 
used (e.g., Daumiller et al. 2016). This approach follows the research of Tschannen-Moran and Woolfolk Hoy (2001) who distinguished between self-efficacy regarding instruction, classroom management, and student engagement/motivation (see Nie, Lau, and Liau 2012). Such a specific differentiation is necessary to ensure the content validity of a self-efficacy scale. At the same time, the entire construct is relevant and may be evaluated on a total construct level, especially in cases when there are no hypotheses for the different facets of self-efficacy, as in the present research in which we postulate that overall-self-efficacy is positively associated with the use of content-related humor.

\section{Achievement goals, self-efficacy, and use of content-related humor: research questions, hypotheses, and overview about the current research}

Based on the relevance of content-related humor in higher education and the importance of knowing about personal aspects behind its use, the current work suggests a motivational approach. For this, we investigated the relevance of teachers' achievement goals and self-efficacy beliefs for the use of content-related humor. Our main research question was to explore the associations of these constructs with teachers' use of content-related humor.

In particular, we expected (1a) performance approach goals and (1b) relational goals to be positively associated with the use of content-related humor and (1c) performance avoidance goals to be negatively associated with the use of content-related humor. In contrast, we had no directed hypotheses for (1d) learning goals and (1e) work avoidance goals. Besides the achievement goals, we expected (2) teachers' self-efficacy beliefs to be positively associated with the use of contentrelated humor. We expected these associations to be robust under the inclusion of teachers' gender and teaching experience (which we assumed to be positively related to content-related humor) as well as the size of the course (which we assumed to be negatively related to content- 
related humor). Furthermore, we wanted to test whether appearance or normative aspects of performance are differentially relevant for the effects of performance goals.

To answer these research questions, we used data from two large-scale studies ${ }^{1}$ that are both based on teacher reports of their achievement goals and self-efficacy beliefs, and on students' assessment of teaching quality using the SEEQ (Marsh 1982). The latter constitutes a viable approach for investigations into teachers' use of content-related humor, since this is included in the form of a single item in the enthusiasm dimension besides dynamic and energetic teaching (see Keller, Hoy, Goetz, and Frenzel 2016). To allow for high generalizability of our results, two approaches were used in the two studies, analyzing the associations on the course level and on the session level: In Study 1, teachers' achievement goals and self-efficacy beliefs were reported with regard to one of their courses; while the students of this course estimated the teachers' use of content-related humor in the course. In Study 2, the teachers assessed their goals and self-efficacy beliefs regarding a specific session of a course; and the students reported the extent of content-related humor used in this specific session. In both studies, the teachers participated with several courses/sessions each.

\section{Study 1}

\section{Method}

In Study 1, 229 teachers (135 male, 79 female, 15 without data on their gender; $159 \mathrm{PhDs}$, 33 full professors) made assessments of their achievement goals and self-efficacy beliefs

\footnotetext{
${ }^{1}$ Specifically, for Study 1 our analyses are based on the dataset reported in Daumiller et al. (2016), and for Study 2 we used data from the first measurement point and the first cohort of a larger study by Daumiller et al. (2019). All data and codes that support the findings of this study are provided in an open access repository (https://osf.io/qzbj8). To confirm that the sample sizes were adequate for the investigation at hand, we conducted power analyses (using MLPowSim; Browne, Lahi, and Marker [2009]). We used conservative settings based on the data and the intended analyses and found that at least 37 instructors were required to detect the effects of the variables on level 2.
} 
regarding 387 courses that were evaluated by 10,296 students. 151 teachers participated with one course, 41 with two, 19 with three, 9 with four, and 9 with five or more courses.

To assess the achievement goals, we used the item stem "In this course...", followed by four items for each goal class: learning goals (e.g. “...I want to further develop my own competences", $\alpha=.89$ ), performance approach goals and performance avoidance goals (each incorporating appearance and normative aspects in a balanced way; e.g. " ... it is important to me to be perceived as competent" for appearance focus and "...it is my goal not to do badly in comparison to fellow instructors" for normative focus, $\alpha=.84, \alpha=.80$ ), relational goals (e.g. “...it is my main objective to establish a positive relationship with my students", $\alpha=.79$ ), and work avoidance goals (e.g. "... it is my goal to have to put in as little effort as possible", $\alpha=.95$; for a more detailed description of this scale, see Daumiller et al. [2016]). All items were to be answered on a Likert-like scale ranging from 1 (I do not agree at all) to 8 (agree completely).

Self-efficacy beliefs were measured by slightly adapting a teacher self-efficacy scale by Nie et al. (2010). We asked the participants to assess themselves regarding instruction, motivation, and classroom management in each course with four items each (e.g., for instruction: "How well do you manage, in this course, to present alternative explanations or examples, if the students do not instantly understand something?”, $\alpha=.86$ ) on a Likert-like scale ranging from 1 (absolutely not good) to 8 (exceedingly good).

Content-related humor was measured by an item of the SEEQ (Marsh, 1982; "Instructor enhances presentations with the use of humor"). It was assessed by the students on a Likert-like scale from 1 (I do not agree at all) to 5 (I absolutely agree).

Teaching experience was measured by six different categories (less than 2 years, $2-5$ years, 6-10 years, 11-15 years, 16-20 years, 21 years or more). 
To analyze the data, we used three-level-analyses (student data nested within courses, nested within teachers) that were estimated with Mplus using Bayesian estimation. Gender, teaching experience, and the number of students per course were used as control variables. We modeled correlations between goals and self-efficacy as well as between gender and teaching experience.

\section{Results}

There was substantial variance in the student assessments of the teachers' use of contentrelated humor (see Table 1). An estimation of the variance components based on the nested answers within courses and within teachers indicated that the use of humor could be attributed to differences between the individual courses within teachers $(\mathrm{ICC}=.13)$ and to differences between the teachers $(\mathrm{ICC}=.21)$.

The three-level models (see Table 2) indicated that students reported a higher use of content-related humor for teachers who had strong relational goals and high self-efficacy beliefs. Conversely, students assessed the use of content-related humor as lower, the more performance avoidance goals their teacher reported. Furthermore, the students reported less content-related humor the larger the courses were, and more humor for female teachers than for male teachers and for teachers with longer teaching experience. Overall, almost one third of the variance of the content-related humor was explained, mostly due to the achievement goals.

Since for performance goals, appearance and normative aspects were assessed conflated together, we could not yet investigate whether appearance and/or normative aspects of performance are relevant for the effects of performance avoidance goals on the use of contentrelated humor. Hence, we focused in Study 2 on these aspects in detail by assessing appearance and normative goals separately. 


\section{Study 2}

\section{Method}

The design of Study 2 was similar to Study 1, but in contrast to the previous study, we focused the assessments on individual sessions instead of courses as a whole. Fourty-five teachers (20 female, 25 male, 27 PhDs, 9 full professors) participated by making assessments regarding their achievement goals and self-efficacy beliefs at the beginning of 116 sessions in different courses. At the end of the sessions, a total of 2,333 students evaluated the humor in each session like in Study 1. Sixteen teachers participated with one course, 17 with two courses, 8 with three courses, and 4 with four or more courses.

In order to only cause minimal disturbances, we used single-items to assess teachers' achievement goals and self-efficacy beliefs at the beginning of the session. Specifically, we used the most face-valid items with high item-total correlations from Daumiller et al. (2019) and Nie et al. (2010). Based on the current session ("In today's session of this course, it is my goal...”) we asked the teachers to assess their learning approach goals (“...to further develop my own competences as much as possible”), relational goals (“...to achieve a personal connection with students"), and work avoidance goals (“...to have the least amount of work as possible”) similarly to Study 1. Performance goals were bifurcated depending on their focus on appearance and normative aspects: We assessed appearance approach goals (“...that other people notice how good my teaching is"), appearance avoidance goals (“...that others don’t think my teaching is bad"), normative approach goals (“...to teach better than my colleagues”), and normative avoidance goals (“...to not teach worse than my colleagues do”). To investigate possible differences in the effects of appearance or normative focus on the use of humor, we conducted the analyses twice, once modeling performance approach/avoidance goals as appearance goals 
and once as normative goals. Self-efficacy beliefs were measured with one item for each of the three facets, instruction, motivation, and classroom management (e.g. for instruction: "What do you think in regard to today's session of this course: How well can you provide an alternative explanation or example when students are confused?"). Additionally, years of teaching experience were assessed. Achievement goals and self-efficacy beliefs were to be answered on a Likert-like scale ranging from 1 (do not agree at all) to 8 (agree completely).

To analyze the data, we ran three-level-analyses (student data nested within sessions, nested within teachers) like in Study 1.

\section{Results}

The results of Study 2 showed similar descriptive statistics as Study 1. For the single sessions, substantial variance in the student assessments of the use of content-related humor was observed (see Table 3). Estimating the variance components using the three-level modeling pointed to similar results as before: The use of humor could be attributed to almost one sixth to differences between the individual sessions within teachers $(\mathrm{ICC}=.12)$, and to one fifth to differences between the teachers $(\mathrm{ICC}=.21)$.

Similar to Study 1, the multilevel analyses (see Table 4) documented a high relevance of relational goals: Teachers stating strong preferences for this goal class at the beginning of the session were rated more positively by the students regarding the use of content-related humor in this session. Also as in Study 1, performance avoidance goals were related to assessments of less humor. The differentiation between appearance and normative aspects indicated that this negative association could exclusively be attributed to appearance avoidance goals. Conducting the analyses with normative goals instead of appearance goals, we found that this goal class was no longer a statistically significant predictor of content-related humor. Furthermore, appearance 
approach goals went along with increased student reports of content-related humor. In contrast to Study 1 however, we did not find statistically significant associations between self-efficacy and the use of humor. Lastly, even though the course size was a negative predictor for content-related humor as in the previous study, teachers' gender and teaching experience were not statistically significant. Overall, as in Study 1, the predictors explained a large amount of variance (over one half), which was mainly due to the teachers' achievement goals.

\section{Overall Discussion}

In this paper, we investigated differences between teachers' use of content-related humor in higher education teaching using a motivational framework consisting of achievement goals and self-efficacy beliefs. To analyze the associations between these motivational aspects and the use of humor, we conducted three-level analyses based on data from teachers and students of two studies. Our results pointed out that especially relational goals and appearance avoidance goals were important predictors for the use of content-related humor. Strengths lie in the two different studies that vary in their approaches used (course-specific and session-specific assessments), the consideration of the multi-level structure, as well as the use of student reports (instead of selfreports) for assessing teachers' use of content-related humor.

Regarding teachers' learning and work avoidance goals, we did not find any relevant associations with their use of content-related humor in both studies. However, considering our assumptions, this may not be surprising since the pursuit of these goal classes is primarily directed at themselves and not on others (as it is the case with relational goals and appearance goals). Consequently, it might be that the strength to which these goals are pursued, is simply not relevant for the content-related humor shown in class. Nevertheless, it is possible that these goals are relevant for the use of humor but might operate rather indirectly, e.g. mediated through higher 
(or lower) satisfaction when teaching, and/or more positive (or negative) emotions, which are known to be consequences of learning and work avoidance goals (Butler 2014). These findings are also relevant for understanding the effects of these goal classes on teachers' cognitions and behaviors when teaching. In these contexts, learning and work avoidance goals may not be categorically functional or dysfunctional, but rather so regarding specific aspects (for a similar argument on learning and task goals in the teaching domain, see Daumiller et al. [2019]).

The negative effects for performance avoidance goals fit well to the unfavorable associations that have been reported of this goal class in the literature on teacher goals (for an overview, see Butler [2014]). Theoretically, these associations seem plausible since using humor can constitute a threat to self-worth: teachers who have strong performance avoidance goals may be afraid of using humor, as they cannot be sure that students will actually perceive it as funny and worry they may be perceived negatively instead. This explanation seems particularly valid as our findings indicated that this maladaptive association of performance avoidance goals is especially found when the focus lies on appearance (and not when focused on normative aspects of performance). In contrast, normative avoidance goals might not be associated with the use of content-related humor as a teacher who does not want to be worse than others (while not strongly fearing to make a bad impression) might attempt to use just as much humor as other teachers.

Besides this, the positive associations that we found for performance approach goals were in agreement with our expectations, however only found in Study 2. It is possible that in the first study, the effects of performance approach goals were masked by not differentiating between appearance and normative aspects. Together with the findings regarding performance avoidance goals, this highlights the importance of differentiating performance goals further, based on their focus on appearance or normative aspects (see also Elliot [2005]; Hulleman et al. [2010]; Lee and 
Bong [2016]; Senko and Dawson [2017]; Urdan and Mestas [2006]). Strong appearance approach goals having been found to be related to a higher use of content-related humor (an aspect related to high-quality teaching) is also in line with Daumiller et al. (2019) who found appearance approach goals to be positively associated with self-reported teaching quality. Using contentrelated humor might be a way for teachers to reach their appearance goals (and possibly also good teaching quality) and leave a good impression on their students. A worthwhile direction of future research is to investigate in more detail how appearance approach goals for teachers function, specifically regarding their use of content-related humor. Here, moderators should be included to investigate for which groups of teachers these effects are especially found in (e.g. it is possible that very competent teachers pursue strong appearance approach goals) or if these effects can be drawn back mainly to people who do not care about their appearance. These research directions are also highly important for practical implications.

As expected, the favorable effects that we found for relational goals for the use of content-related humor in both studies, emphasize the role of humor in interpersonal contexts such as teaching. The instrumental function of humor for relational goals can be explained by the social aspect of humor which can help to reduce strict hierarchies by means of positive interactions in a friendly spirit (Ziv 2010). Specifically, the use of content-related humor could be a mediating factor for the effects of relational goals on favorable teaching outcomes documented in the previous literature (Butler 2012; Daumiller et al. 2016; Daumiller et al. 2019).

Lastly, the positive effects of self-efficacy matched our expectations and imply that a fair amount of self-efficacy may be necessary for successfully using content-related humor when teaching. However, these results should be interpreted with caution, as they were only found in Study 1. One reason for these missing effects in the second study could be the different levels of 
specificity used in both studies. Indeed, substantial differences in the session-specific or coursespecific assessment of teachers' self-efficacy beliefs are plausible. For example, a teacher may report low session-specific self-efficacy beliefs, because he/she did not prepare well for the current session, while at the same time holding high overall self-efficacy beliefs for teaching. This might be especially relevant for the use of content-related humor in class that often happens incidentally and is not specifically prepared for. For future research, it might therefore be important to clearly distinguish the level of self-efficacy beliefs (regarding teaching in general, or the challenges of a specific, upcoming course session) to understand their relevance for the use of humor in more detail.

Taken together, these findings point to the importance of achievement goals and selfefficacy beliefs for teachers' use of content-related humor (especially when considering the substantial amount of explained variance). Specifically, we found the effects of these motivational constructs on the use of content-related humor controlling for course size, gender, and teaching experience, which, along our expectations, were also relevant for the student assessments of humor. Taking the small sample size on the teacher level in Study 2 and the results of our power analyses into consideration, it may not be surprising that we only found the effects of gender and teaching experience in the first study. The influence of the course size is in line with previous research on the difficulties of teaching large classes (Arvanitakis 2014) and implies that it is more difficult to create content-related humor in courses with many participants. Moreover, the effects regarding teaching experience and gender coincide with the assumption that humor in teaching is a didactic competence that is difficult to learn and that humor by women is received as less funny and used less often (Bryant et al. 1979).

\section{Limitations, practical implications, and conclusion}


Although the study at hand has many strengths, there are limitations within the design that should be considered when interpreting the results. As we assessed content-related humor using economic single items that were only assessed by the students, it cannot be ruled out that some of these assessments might have been biased, e.g. because students liked or disliked the instructors in question. Although this limitation is reduced since we used multiple raters (instead of multiple items), this needs to be acknowledged. For future research, it would therefore be beneficial to include more items and possible bias variables (e.g. affinity towards the instructor). Additionally, it might be useful to include further sources on the humor exhibited (e.g. observations of the lectures that are subsequently analyzed).

Despite these limitations and this study being the first of its kind to investigate the effects of teacher achievement goals and self-efficacy on content-related humor, preliminary practical implications can already be drawn. Specifically, professional development should, among other aspects, also consider motivational factors and in doing so focus on carefully reflecting university instructors' relational and appearance avoidance goals while emphasizing the increase and enhancement of low self-efficacy for teaching. From our findings it can be considered as especially beneficial to support teachers in finding ways to foster relational goals, particularly in large lectures. Besides this, strong appearance avoidance goals should be reduced, e.g. by reducing fear of the teachers and strengthening their trust in themselves. In summary, a motivational approach to explain differences in teachers' use of content-related humor in higher education seems promising and highlights the relevance of achievement goals and self-efficacy beliefs for humorous higher education. 


\section{References}

Arvanitakis, J. 2014. Massification and the large lecture theatre: From panic to excitement. Higher Education 67: 735-745. doi:10.1007/s10734-013-9676-y

Bailey, J. 1999. Academics' Motivation and Self-efficacy for Teaching and Research. Higher Education Research \& Development 18(3): 343-359.

Banas, J., N. Dunbar, D. Rodriguez, and S.-J. Liu. 2011. A Review of Humor in Educational Settings. Communication Education 60(1): 115-144. doi:10.1080/03634523.2010.496867.

Bandura, A. 1977. Self-efficacy. Psychological Review 84: 191-215. doi:10.1037//0033295x.84.2.191.

Bandura, A. 1997. Self-efficacy: The Exercise of Control. New York, NY: Freeman.

Berk, R. A. 1996. Student Ratings of 10 Strategies for Using Humor in College Teaching. Journal on Excellence in College Teaching 7(3): 71-92.

Bieg, S., and M. Dresel. 2018. Relevance of Perceived Teacher Humor Types for Instruction and Student Learning. Social Psychology of Education 21: 1-21. doi:10.1007/s11218-0189428-z.

Bieg, S., R. Grassinger, and M. Dresel. 2017. Humor as a Magic Bullet. Learning and Individual Differences 56: 24-33. doi:10.1016/j.lindif.2017.04.008.

Bieg, S., R. Grassinger, and M. Dresel. 2018. Teacher humor: Longitudinal effects on students' emotions. European Journal of Psychology of Education: 1-18. doi:10.1007/s10212-0180402 
Booth-Butterfield, M., and M. Wanzer. 2010. Humor and Communication in Instructional Contexts. In The SAGE Handbook of Communication and Instruction, edited by D. L. Fassett and J. T. Warren, 221-239. Thousand Oaks, CA: Sage.

Booth-Butterfield, S., and M. Booth-Butterfield. 1991. Individual Differences in the Communication of Humorous Messages. Southern Communication Journal 56(3): 205218. doi:10.1080/10417949109372831.

Browne, W., Lahi, M., and R. Parker. 2009. A Guide to Sample Size Calculations for Random Effect Models via Simulation and the MlPowSim Software Package [Computer program and manual]. Retrieved from http://www.bristol.ac.uk/cmm/software/mlpowsim/

Bryant, J., P. Comisky, J. Crane, and D. Zillmann. 1980. Relationship Between College Teachers' Use of Humor in the Classroom and Students' Evaluations of their Teachers. Journal of Educational Psychology 72(4): 511-519. doi:10.1037/0022-0663.72.4.511.

Bryant, J., P. Comisky, and D. Zillmann. 1979. Teachers' Humor in the College Classroom. Communication Education 28(2): 110-118. doi:10.1080/03634527909378339.

Butler, R. 2007. Teachers' Achievement Goal Orientation and Association with Teachers' Helpseeking. Journal of Educational Psychology 99: 241-252. doi:10.1037/00220663.99.2.241.

Butler, R. 2012. Striving to Connect. Journal of Educational Psychology 104: 726-742. doi:10.1037/a0028613.

Butler, R. 2014. What Teachers Want to Achieve and why it Matters. In Teacher motivation: Theory and practice, edited by P. Richardson, S. Karabenick, and H. Watt, 20-35. New York, NY: Routledge. 
Daumiller, M., J. Hein, R. Rinas, S. Janke, O. Dickhäuser, and M. Dresel. 2019. Temporal Variability and Domain Specificity of University Instructors' Achievement Goals and Associations with Affective Experiences. Paper presented on the 2019 American Educational Research Association (AERA) Annual Meeting, Toronto, Canada.

Daumiller, M., O. Dickhäuser, and M. Dresel. 2019. University Instructors’ Achievement Goals for Teaching. Journal of Educational Psychology 111, 131-148. doi:10.1037/edu0000271.

Daumiller, M., R. Grassinger, O. Dickhäuser, and M. Dresel. 2016. Structure and Relationships of University Instructors' Achievement Goals. Frontiers in Psychology. doi:10.3389/fpsyg.2016.00375.

Delaney, J., A. Johnson, T. Johnson, and D. Treslan. 2010. Students'Perceptions of Effective Teaching in Higher Education. University of Newfoundland, St. John's, Newfoundland.

Dweck, C. 1986. Motivational Processes Affecting Learning. American Psychologist 41(10): $1040-1048$.

Elliot, A. 2005. A Conceptual History of the Achievement Goal Construct. In Handbook of competence and motivation, edited by A. Elliot and C. Dweck, 52-72. New York, NY: Guildford.

Elliot, A., and C. Hulleman. 2017. Achievement Goals. In Handbook of competence and motivation, edited by A. J. Elliot, C. S. Dweck, and D. S. Yeager, 43-60. New York, NY: Guilford.

Elliott, E., and C. Dweck. 1988. Goals. Journal of Personality and Social Psychology 54(1): 512. 
Forester, M., J. Kahn, and M. Hesson-McInnis. 2004. Factor Structures of Three Measures of Research Self-efficacy. Journal of Career Assessment 12(1): 3-16.

Frymier, A., M. Wanzer, and A. Wojtaszcyk. 2008. Assessing Students’ Perceptions of Inappropriate and Appropriate Teacher Humor. Communication Education, 57 (2): 266288. doi:10.1080/03634520701687183.

Hemmings, B., and R. Kay. 2009. Lecturer Self Efficacy. Issues in Educational Research 19(3): $243-254$.

Horng, J.-S., J.-C. Hong, L.-J. ChanLin, S.-H. Chang, and H.-C. Chu. 2005. Creative Teachers and Creative Teaching Strategies. International Journal of Consumer Studies 29: 352358. doi:10.1111/j.1470-6431.2005.00445.x.

Hulleman, C., S. Schrager, S. Bodmann, and J. Harackiewicz. 2010. A Meta-analytic Review of Achievement Goal Measures. Psychological Bulletin 136: 422-449. doi:10.1037/a0018947.

Javidi, M., and L. Long's. 1989. Teacher' Use of Humor, Self-disclosure, and Narrative Activity as a Function of Experience. Communication Research Reports 6(1): 47-52. doi:10.1080/08824098909359831.

Keller, M., A. Hoy, T. Goetz, and A. Frenzel. 2016. Teacher Enthusiasm. Educational Psychology Review 28: 743-769. doi:10.1007/s10648-015-9354-y

Klassen, R. T. Durksen, and V. Tze. 2014. Teachers' Self-efficacy Beliefs. In Teacher motivation, edited by P. Richardson, S. Karabenick, and H. Watt, 100-115. New York, NY: Routledge. 
Lee, M., and M. Bong, 2016. In Their Own Words. Journal of Educational Psychology 108: 274294. doi:10.1037/edu0000048.

Lee, H., G. Kim, and L. Chan. 2013. Good Teaching. Asia Pacific Journal of Education 35(1): 98-110. doi:10.1080/02188791.2013.860008.

Liu, Y., Sun, L., Wu, X., Yang, Y., Zhang, C., Zhou, H., and X. Quan. 2017. Use of Humour in Medical Education: A Survey of Students and Teachers at a Medical School in China. BMJ Open 7: 1-7. doi:10.1136/bmjopen-2017-018853.

Maehr, M., and A. Zusho. 2009. Achievement Goal Theory. In Handbook of Motivation at School, edited by K. Wenzel and A. Wigfield, 78-104. New York, NY: Routledge. Major, C., and J. Dolly. 2003. The Importance of Graduate Program Experiences to Faculty Selfefficacy for Academic Tasks. The Journal of Faculty Development, 2: 89-100.

Martin, D., R. Preiss, W. Gayle, and N. Allen. 2006. A Meta-Analytic Assessment of the Effect of Humorous Lectures on Learning. In Classroom Communication and Instructional Processes, edited by B. Gayle, R. Preiss, N. Burrell, and M. Allen, 295-314. Mahawa, NJ: Lawrence Erlbaum.

McKeachie, W., and M. Svinicki. 2006. Teaching Tips: Strategies, Research, and Theory for College and University Teacher. New York, NY: Houghton Mifflin.

Nicholls, J. 1984. Achievement Motivation. Psychological Review 91(3): 328-346. doi:10.1037/0033-295X.91.3.328.

Nie, Y, S. Lau, and A. Liau. 2012. The Teacher Efficacy Scale. The Asia-Pacific Education Researcher 21(2): 414-421. 
Nitsche, S., O. Dickhäuser, M. S. Fasching, and M. Dresel. 2011. Rethinking Teachers’ Achievement Goals. Learning and Instruction 21(4): 574-586. doi:10.1016/j.learninstruc.2010.12.001.

Powell, J., and L. Andresen. 1985. Humor and Teaching in Higher Education. Studies in Higher Education 10: 79-90. doi:10.1080/03075078512331378726.

Ross, J. A. 1992. Teacher Efficacy and the Effects of Coaching on Student Achievment. Canadian Journal of Education 17: 51-65. doi:10.2307/1495395.

Ruch, W. 2001. The Perception of Humor. In Emotions, qualia, and consciousness, edited by A. Kaszniak, 410-425. River Edge, NJ: World Scientific.

Schrader, F.-W., A. Helmke, I. Hosenfeld, and A. Ridder. 2001. Klassengröße und Mathematikleistung [Class Size and Mathematics Performance]. Empirische Pädagogik 15: $601-625$.

Schunk, D., J. Meece, and P. Pintrich. 2013. Motivation in Education: Theory, Research, and Applications. Saddle River, NJ: Pearson.

Senko, C., and B. Dawson. 2017. Performance-approach Goal Effects Depend on how they are Defined. Journal of Educational Psychology 109(4): 574-598. doi:10.1037/edu0000160.

Sev'er, A., and S. Ungar. 1997. No Laughing Matter. The Journal of Higher Education 68(1): 87-105. doi:10.1080/00221546.1997.11778978.

Tschannen-Moran, M., and A. Woolfolk Hoy. 2001. Teacher Efficacy. Teaching and Teacher Education 17(7): 783-805. doi: 10.1016/S0742-051X(01)00036-1.

Vallance, E. 1980. A Deadpan Look at Humor in Curriculum Discourse. Curriculum Inquiry 10: 179-189. doi:10.1080/03626784.1980.11075214. 
Wanzer, M., A. Frymier, A. Wojtaszczyk, and T. Smith. 2006. Appropriate and Inappropriate Uses of Humor by Teachers. Communication Education 55(2): 178-196. doi:10.1080/03634520600566132.

Wiegfield, A. and J. Eccles. 2000. Expectancy-value Theory of Achievement Motivation. Contemporary Educational Psychology 25: 68-81. doi:10.1006/ceps.1999.1015

Ziv, A. 2010. The Social Function of Humor In Interpersonal Relationships. Society 47(1): 1118. 
Table 1

Descriptive Statistics and Correlations of Content-related Humor, Achievement Goals and Self-efficacy Beliefs in Study 1

\begin{tabular}{|c|c|c|c|c|c|c|c|c|c|c|c|c|c|c|}
\hline & $M$ & $S D$ & Min & $\operatorname{Max}$ & Skew & 1 & 2 & 3 & 4 & 5 & 6 & 7 & 8 & 9 \\
\hline \multicolumn{15}{|l|}{ Level 3: Teacher } \\
\hline [1] Teaching experience & 2.60 & 1.48 & 1.0 & 6.0 & 0.83 & & & & & & & & & \\
\hline [2] Gender $(0=$ male, $1=$ female $)$ & 0.37 & 0.48 & 0.0 & 1.0 & 0.55 & -.23 & & & & & & & & \\
\hline \multicolumn{15}{|l|}{ Level 2: Course } \\
\hline [3] Course size & 26.60 & 29.60 & 3.0 & 279.0 & 4.81 & .06 & -.08 & & & & & & & \\
\hline [4] Learning goals & 6.36 & 1.38 & 1.0 & 8.0 & -1.05 & -.05 & .18 & -.11 & & & & & & \\
\hline [5] Performance approach goals & 5.18 & 1.63 & 1.0 & 8.0 & -0.37 & -.09 & -.07 & .11 & .12 & & & & & \\
\hline [6] Performance avoidance goals & 6.09 & 1.42 & 1.0 & 8.0 & -0.92 & -.09 & .01 & .05 & .13 & .81 & & & & \\
\hline [7] Relational goals & 5.91 & 1.27 & 1.5 & 8.0 & -0.65 & .06 & .05 & -.13 & .40 & .19 & .17 & & & \\
\hline [8] Work avoidance goals & 2.97 & 1.75 & 1.0 & 8.0 & 0.72 & .02 & -.05 & .04 & -.12 & .30 & .22 & -.04 & & \\
\hline [9] Self-efficacy & 6.28 & 0.79 & 2.4 & 8.0 & -0.85 & .18 & -.06 & -.13 & .27 & .20 & .23 & .31 & -.17 & \\
\hline \multicolumn{15}{|l|}{ Level 1: Students } \\
\hline Content-related humor & 3.71 & 1.10 & 1.0 & 5.0 & -0.51 & .25 & -.25 & -.15 & -.01 & -.01 & -.06 & .14 & .02 & .15 \\
\hline
\end{tabular}

Notes. $N($ students $)=10,296, N($ courses $)=387, N($ teachers $)=230$. Reported are bivariate correlations on the course level (all statistically significant correlations are boldfaced, $|r| \geq .10: p<.05)$. Due to the substantial skew, we logarithmically rescaled the amount of participants in the courses in order to ensure a normal distribution, course-size $e_{\text {new }}:=\ln ($ course-size $): M=3.00, S D=0.68$, range $=1.1-5.6$, skew $=0.72$. 
Table 2

Study 1: Three-Level-Analyses on the Effects of Teachers' Achievement Goals and Self-Efficacy Beliefs on Content-related Humor

\begin{tabular}{lc}
\hline & $\beta$ (S.E.) \\
\cline { 2 - 2 } Level 2: Courses & $.01 \quad(.09)$ \\
Learning (approach) goals & $.13 \quad(.13)$ \\
Performance approach goals & $-.23^{*}(.13)$ \\
Performance avoidance goals & $.17^{*}(.09)$ \\
Relational goals & $.09 \quad(.08)$ \\
Work avoidance goals & $.16^{*}(.08)$ \\
Self-efficacy & $-.16^{*}(.07)$ \\
Course size & .14 \\
$R^{2}$ & \\
Level 3: Teachers & $-.24 * *(.08)$ \\
Gender & $.24 * *(.09)$ \\
Teaching experience & .15 \\
$R^{2}$ & \\
\hline
\end{tabular}

Notes. $n_{\text {students }}=10,296, n_{\text {courses }}=387, n_{\text {teachers }}=229$. Reported are standardized posterior probabilities that can be reported like regular regression parameters. Posterior predictive $p$ value: .16. ${ }^{*} p<.05 . * * p<.01 . * * * p<.001$. 
Table 3

Descriptive Statistics and Correlations Between Content-related Humor, Achievement Goals and Self-efficacy Beliefs in Study 2

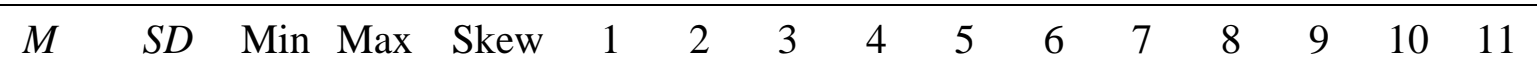

\begin{tabular}{|c|c|c|c|c|c|c|c|c|c|c|c|c|c|}
\hline \multicolumn{14}{|c|}{ Level 3: Teacher } \\
\hline$[1]$ & Teaching experience (in years) & 11.43 & 8.28 & 1.0 & 30.0 & 0.60 & & & & & & & \\
\hline$[2]$ & Gender $(0=$ male, $1=$ female $)$ & 0.44 & 0.50 & 0.0 & 1.0 & 0.23 & -.11 & & & & & & \\
\hline \multicolumn{14}{|c|}{ Level 2: Session } \\
\hline$[3]$ & Course size & 21.48 & 27.92 & 4.0 & 232.0 & 4.99 & $.21-.09$ & & & & & & \\
\hline$[4]$ & Learning goals & 5.14 & 2.04 & 1.0 & 8.0 & -0.26 & $-.01-.25-.01$ & & & & & & \\
\hline$[5]$ & Appearance approach goals & 4.36 & 2.05 & 1.0 & 8.0 & -0.19 & $-.28 \quad .11-.01$ & .24 & & & & & \\
\hline$[6]$ & Appearance avoidance goals & 4.18 & 2.15 & 1.0 & 8.0 & 0.08 & $\begin{array}{lll}-.33 & .37 & .16\end{array}$ & .16 & .54 & & & & \\
\hline [7] & Normative approach goals & 3.20 & 1.81 & 1.0 & 8.0 & 0.61 & $\begin{array}{lll}-.21 & .01-.12\end{array}$ & .29 & .53 & .50 & & & \\
\hline$[8]$ & Normative avoidance goals & 4.38 & 2.16 & 1.0 & 8.0 & -0.01 & $\begin{array}{lll}-.10 & .11 & .01\end{array}$ & .28 & .45 & .56 & .42 & & \\
\hline$[9]$ & Relational goals & 3.88 & 2.36 & 1.0 & 8.0 & 0.29 & $\begin{array}{lll}-.22 & .14-.08\end{array}$ & -.12 & .17 & .20 & $.25 \quad .05$ & & \\
\hline$[10$ & Work avoidance goals & 3.62 & 1.74 & 1.0 & 6.0 & -0.10 & $.06-.01-.09$ & .11 & .09 & -.04 & $\begin{array}{lll}.02 & .02 & .01\end{array}$ & & \\
\hline$[11$ & Self-efficacy beliefs & 6.48 & 1.09 & 2.7 & 8.0 & -0.85 & $\begin{array}{lll}-.02 & .12 & -.17\end{array}$ & .13 & .13 & .03 & $.21 \quad .08-.07$ & .26 & \\
\hline \multicolumn{14}{|c|}{ Level 1: Students } \\
\hline Cor & tent-related humor & 3.51 & 1.17 & 1.0 & 5.0 & -0.38 & $-.01-.01-.09$ & .01 & .16 & -.01 & $.10-.01 \quad .21$ & .06 & .01 \\
\hline
\end{tabular}

Notes. $N($ students $)=2,333, N($ sessions $)=116, N($ teachers $)=45$. Reported are bivariate correlations on the session level (all statistically significant correlations are boldfaced, $|r| \geq .20: p<.05$ ). As in Study 1, we logarithmically rescaled the amount of participants in the courses in order to ensure a normal distribution, $\ln ($ course-size $): M=2.61, S D=1.01$, range $=1.4-5.5$, skew $=-0.65$. 
Table 4

Study 2: Three-Level-Analyses on the Effects of Teachers' Achievement Goals and Self-Efficacy Beliefs on Content-related Humor

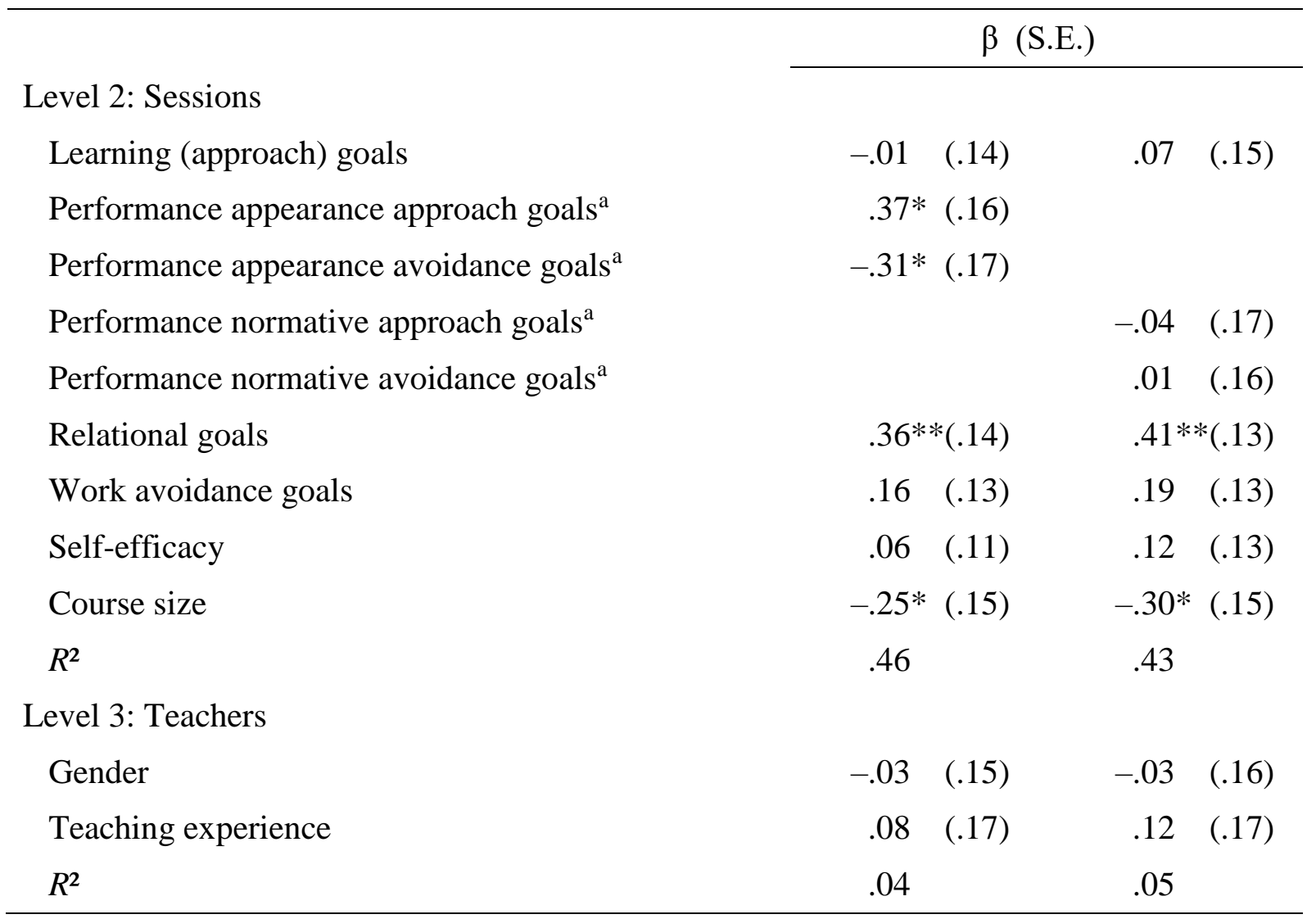

Notes. $n_{\text {students }}=2,333, n_{\text {sessions }}=116, n_{\text {teachers }}=45$. Reported are standardized posterior probabilities that can be reported like regular regression parameters. Posterior predictive $p$-values: .48-.53. $* p<.05 . * * p<.01 . * * * p<.001$.

${ }^{\text {a }}$ We estimated two models in which performance goals were either modeled as appearance goals or as normative goals. 